\title{
Mitral valvar grafts
}

\author{
Marian I. Ionescu \\ From the Department of Cardiothoracic Surgery, the General Infirmary at Leeds and \\ Leeds University
}

While prosthetic valves are acceptable in the subcoronary position, their use for mitral or tricuspid replacement is less satisfactory. Introduced by Ross in 1962, aortic homografts for aortic valve replacement have found a definite place in the modern surgical armamentarium and have paved the way towards heart valve grafting. Naturally, for an improved mitral valve substitute, attention was directed towards the use of biological tissues.

The geometry of the aortic valve is known and partly understood, while the functional anatomy of the complex mitral valve has still to be elucidated. There are several facts that complicate grafting of the mitral valve. There is a greater pressure differential between atrium and ventricle than between ventricle and aorta, and the closure pressure of the mitral valve is higher than that of the aortic valve. The great majority of patients requiring mitral valve replacement are in atrial fibrillation with an enlarged left atrium and consequent propensity to thrombus formation, and they may also have a raised pulmonary vascular resistance. To add to the complexity of the problem the continuously moving mitral annulus has an elliptical shape and is connected with the ventricle by chordae tendineae and papillary muscles.

It is self-evident that a prosthetic device could not produce ideal results in the mitral position and that the construction of a tissue valve similar in function to the normal mitral valve is a great surgical challenge.

\section{Preserved tissue valves}

Following Francis Bacon's philosophy we have started to replace the mitral valve by imitating nature. Preserved mitral homografts and heterografts with or without reinforcement have been used with rather discouraging results. It was difficult to find homografts sufficiently big to match the enlarged mitral annulus of patients. The heterograft valve has slightly different leaflet and chordal sizes and does not accommodate itself well to the human left ventricle. In 1967 we learned from Ross that despite initial success with mitral homografts the majority of his patients developed mitral regurgitation due to rupture of chordae within the first year after operation (Ross, 1967a).

Next, attention was directed towards the use of preserved aortic heterografts for mitral valve replacement. Between February 1967 and March 196974 patients had the mitral valve replaced with supported aortic heterografts either alone or in combination with replacement of other valves (Ionescu et al., 1967, 1968).

Among the first 83 aortic heterografts inserted, several types of supported grafts were used and different procedures were adopted for their sterilization and preservation.

Two basic types of supports have been used. The first 25 grafts were sutured inside a flexible Teflon cloth cylinder. The remaining 58 heterografts were attached to a scallopshaped, Dacron-covered titanium frame.

Concerning sterilization and preservation, there were two main groups of grafts. The first nine were sterilized with beta-propiolactone deep-frozen and freeze-dried and the last 74 grafts were treated with 4 per cent formaldehyde buffered at $p \mathrm{H} 5.6$.

The 59 operative survivors were followed up for between 18 months and $3 \frac{1}{2}$ years. Two patients died owing to graft failure without being reoperated upon and six were reoperated upon but died in the immediate postoperative period. There were six more patients in whom the grafts failed but were successfully replaced. The incidence of graft failure in this series of patients is 23.7 per cent.

At the time of writing this report there are 47 patients alive: 29 with a good result without pathological heart murmurs. Eleven other patients are alive and well, but they have a pathological murmur indicative of valve dysfunction. The remaining seven patients are well after having had their heterografts replaced with another heterograft, with fascia lata grafts, or with Starr valves. 
In the first 40 cases the technique was continuously changed until standardized and in this group with a follow-up of from 31 to 40 months there were 13 graft failures. In the last group of 37 patients followed-up from 15 to 30 months there was only one graft failure. It is interesting to note that the majority of failures happened during the first three to 20 months after surgery. With the exception of two patients in whom mechanical rupture of the graft occurred suddenly the majority of patients whose valves subsequently failed developed a regurgitant murmur during the first six months.

In I I other patients with a regurgitant murmur, the murmur appeared very soon after surgery (from immediately to 12 weeks postoperatively). Only two of these eleven patients seem to require reoperation.

\section{Causes of failure}

From our experience of mitral valve replacement with preserved supported aortic heterografts over a period of $3 \frac{1}{2}$ years several conclusions can be drawn.

The haemodynamic characteristics and freedom from thromboembolism without anticoagulants are definite advantages. Unfortunately the high incidence of early graft failure in our series shows that, at least in its present state, the method does not justify the initial enthusiasm. The causes of graft failure are multiple and complex:

I) Some of them are due to mechanical faults in the preparation of the grafts. This can be avoided by proper selection of graft sizes, by extreme care in suturing, and by using an adjustable frame support (Kaiser et al., r969).

2) The biological factors implicated in graft failure are not yet very clearly defined, but it seems that the method of sterilization and preservation is of crucial importance. Betapropiolactone proved to be too aggressive for the tissues. Buffered formaldehyde, on the other hand, was found to be too weak a tanning agent. The antigenic potential of the heterograft is not abolished and microscopical examination of failing grafts (Sutherland, I970) showed a rejection-like reaction. It seems probable that such histological changes are responsible for graft degeneration and failure, at least in some of the cases.

Sterilization and preservation of grafts could be improved by using either a better tanning agent such as glutaraldehyde (Carpentier, 1969) or by surface sterilization with antibiotics (Barratt-Boyes, I969). The use of fresh aortic homografts (Angell, 1969) proved to give better results in mitral valve replacement, but the limited availability of such grafts precludes their routine clinical application.

3) It is probable that haemodynamic factors as well are responsible for graft failure. In this respect the geometry of the graft should be changed in order to improve its durability.

\section{Living autologous tissue grafts}

Because there are many unknown factors in the long-term fate and function of preserved grafts, we have turned our attention towards the use of living autologous tissue (Ionescu and Ross, 1969; Ionescu and Deac, 1970). Senning (1970) has been using free fascia lata grafts for aortic valve reconstruction or replacement since 1962 with good results. Ross (I967b) has been using over the past three years the patient's own pulmonary valve for aortic or mitral valve replacement and the results are superior to those obtained with homografts.

We have developed a frame-supported autologous fascia lata graft for use in both the atrioventricular and the aortic positions. Since April 196982 patients ( 7 to 64 years old) had the mitral valve alone or in combination with other valves replaced with 98 fascial grafts. Except for three, all patients were in class III or IV (N.Y.H.A.) preoperatively. In this group of patients there were I3I associated abnormalities and 25 of them had had previous heart valve surgery. In addition 14 other cardiac procedures were performed at the time of valve replacement. There were ro hospital deaths $(12.2 \%)$, none of them being related to the graft per se.

Three patients succumbed after the operative period, two from subacute bacterial endocarditis at 2 and 3 months respectively; one death presumed to be from arrhythmia occurred 2 months postoperatively.

There were a few late complications related to the valve grafts in the 69 survivors. Three patients, with mitral replacement, developed a systolic murmur at the apex (grade $\mathrm{I} / 6$ ), while two others have a grade $2 / 6$ systolic murmur. All five are in a very good clinical condition and four of them are considered to be improved after haemodynamic studies. Radiographs show a reduction in their heart size. The murmurs do not seem to be increasing in intensity with the passage of time.

The cause and mechanism of production of the murmurs is not known, but they could only be produced by regurgitation through or around the graft.

A patient who did not improve after surgery 
was reoperated upon six months after mitral valve replacement. The left atrium was found to be occupied by an enormous friable thrombus partially obstructing the pulmonary veins and adhering to the atrial wall. The only parts of the atrium free from thrombus were the suturing rim of the valve and the fascial graft which looked macroscopically identical to a freshly prepared graft. After removing the thrombus, a minute piece of fascia lata was removed for microscopical examination and the graft left in place. The patient improved immediately and is now on maintenance treatment with anticoagulants. This is the only patient in the series to have anticoagulant treatment.

The remainder of the patients are all very much improved clinically, and haemodynamic studies with exercise tests performed six to eight months postoperatively confirm the clinical impression. In 80 per cent of the patients the diuretic treatment has been discontinued. All patients with isolated mitral, or mitral and tricuspid replacement, have normal heart sounds. In patients with mitral and aortic valve replacement there is a grade $I-2 / 6$ aortic systolic murmur due to the presence of the support frame in the aortic root. Thromboembolic complications have been absent, though anticoagulants have not been used.

When evaluating a method which involves transplantation of tissue, time is the most important single factor. In order to obtain useful information in a shorter period of time, all relevant data are analysed.

The experimental and clinical use of fascia lata in general surgery has shown that after autologous, heterotopic transplantation fascia continues to survive. Histologically the structure of the graft resembles that of normal fascia. There is no evidence of cellular or capillary invasion from the host. Specimens removed up to Io years after transplantation have maintained their normal structure and if exposed to mechanical stimulation have retained their functional properties.

It appears probable that if the fibroblasts continue to live they will 'service' the matrix and therefore preserve the integrity of the transplanted tissue (Gallie and Le Mesurier, I921, 1922, I948).

The clinical use of fascia lata for aortic valve repair or replacement (Senning, 1970) has shown good results up to eight years postoperatively. The structure and function of fascia are well preserved, although definite proof concerning the viability of the fibroblast has not yet been obtained.

Our clinical experience with frame-mouned fascial grafts has shown that in a different haemodynamic situation in the mitral area these grafts perform satisfactorily more than one year after implantation (Ionescu et al., 1970).

\section{Criteria}

There are several criteria to be considered when a heart valve substitute is evaluated. The frame-mounted autologous fascia lata grafts fulfil very well most of them.

The advantages of using biological tissue have already been stressed.

Fascia, being transplanted as an autologous graft, can be transferred to the new site in a viable state. Whether the viability of the entire structure will be maintained for an extended period of time remains to be seen.

The technique of making the grafts at the time of surgery is a reproducible one requiring not more than the usual surgical skill.

The fascial grafts are available in all necessary sizes, being tailored individually for each case.

The surgical insertion is as simple and as rapid as for a prosthetic valve.

The flow characteristics are almost identical to those of a natural aortic valve and the haemodynamic performance has proved itself to be very satisfactory.

Fascial valves seem to be more prone to infection than other valves. With special care this type of complication can be avoided.

Thromboembolic complications are virtually eliminated by the use of fascial grafts even without anticoagulants.

The durability of fascia lata seems to satisfy the requirements of a heart valve. In the aortic position there is good evidence of continued function over a period of eight years. In the mitral position our follow-up is too short to draw any conclusions. The initial results over more than one year are very good.

This method of heart valve replacement will be evaluated over an extended period of time. Its clinical value depends on the ultimate fate and long-term function of the fascial tissue.

\section{References}

Angell, W. W. (1969). The Stanford, fresh homograft experience. Read at the Ist International Workshop on tissue valves. Silverado, October 4 and 5 . (Summary, Annals of Surgery, 1970, 172 (1), Suppl., 8.)

Barratt-Boyes, B. G. (1969). Aortic homografts. Read at the Ist International Workshop on tissue valves. Silverado, October 4 and 5. (Summary, Annals of Surgery, 1970, 172 (I), Suppl., 3.)

Carpentier, A. (1969). Method for preparing cardiac valves and vessels for use in humans. Read at the Ist International Workshop on tissue valves. Silverado, October 4 and 5. (Summary, Annals of Surgery, 1970, 172 (1), Suppl., 12.) 
Gallie, W. E., and Le Mesurier, A. B. (192I). The use of living sutures in operative surgery. Canadian Medical Association fournal, 11, 504.

- and - (1922). A clinical and experimental study of the free transplantation of fascia and tendon. Fournal of Bone and foint Surgery, 4, 600.

- and - (1948). Recurring dislocation of the shoulder. Fournal of Bone and foint Surgery, 30B, 9.

Ionescu, M. I., and Deac, R. C. (1970). Fascia lata composite graft for right ventricular outflow tract and pulmonary artery reconstruction; surgical technique. Thorax, 25, 427.

- and Ross, D. N. (1969). Heart valve replacement with autologous fascia lata. Lancet, 2, 335.

$\longrightarrow$, Deac, R. C., Grimshaw, V. A., Taylor, S. H., Whitaker, W., and Wooler, G. H. (1970). Autologous fascia lata for heart valve replacement. Thorax, 25, 46.

, Wooler, G. H., Smith, D. R., and Grimshaw, V. A. (1967). Mitral valve replacement with aortic heterografts in humans. Thorax, 22, 305.

, Whitaker, W., Smith, D. R., Taylor, S. H., and Hargreaves, M. D. (I968). Heart valve replace- ment with reinforced aortic heterografts. Fournal of Thoracic and Cardiovascular Surgery, 56, 333.

Kaiser, G. A., Hancock, W. D., Lukban, S. B., and Litwak, R. S. (1969). Clinical use of a new design stented xenograft heart valve prosthesis. Surgical Forum, 20, 137.

Ross, D. N. (1962). Homograft replacement of the aortic valve. Lancet, 2,487 .

- (1967a). Mitral homografts. Read at the annual meeting of the Society of Thoracic Surgeons of Great Britain and Ireland. Southampton, September 21 and 22 .

(1967b). Replacement of aortic and mitral valves with a pulmonary autograft. Lancet, 2, 956.

Senning, A. (1970). Aortenklappenersatz durch Fascia lata. Read at the 36th Annual Meeting of the Deutsche Gesellschaft für Kreislaufforschung. Bad Nauheim, April 3-5.

Sutherland, T. W. (1970). Microscopical changes in aortic valve heterografts replacing human heart valves. In Biological Tissue in Heart Valve Replacement, Ed. by M. I. Ionescu, D. N. Ross, and G. H. Wooler. Butterworths, London. In press. 